\title{
The Reliability of the Distally Based Peroneus Brevis Muscle Flap for Coverage of the Skin Defects Over the Tendo-Achilis
}

\author{
KHALED A. REYAD, M.D. and RAGHDA E. TALLAL, M.D. \\ The Department of Plastic and Maxillofacial Surgery, Faculty of Medicine, Ain Shams University, Cairo, Egypt
}

\begin{abstract}
Soft tissue and bone defects of the lower leg, around the ankle, and more distal regions always require coverage by large local or distant flaps. Authors used the distally based peroneus brevis muscle flap for the treatment of 10 patients with soft tissue defects over the tendo-achilis: That occurred after extensive dissection of skin jeopardizing its vascularity or after tendo-ahilis grafting by fascia-lata to reconstruct tendo-achilis. All defects were small to medium sized between 10.56 to $21.84 \mathrm{~cm}^{2}$. All flaps passed without major complications. The distally based peroneus brevis muscle represents a very reliable flap for coverage of small and medium defects over the tendo-achilis and may be preferable to the use of free flaps.
\end{abstract}

\section{INTRODUCTION}

Despite of the great steps in the field of microvascular reconstructive surgery, the reconstruction of soft tissue defects of lower one third of the lower limb may pose difficulties especially with significant vascular compromise. Reconstruction of soft tissue defects in the lower one third of the leg and foot usually mandates coverage using local or distant flaps owing to exposed hard ware, tendon or bone. Reconstructive options usually comprise local cutaneous flaps, fascial or fasciocutaneous flaps, muscle flaps, and free flaps [1-3]. Moreover, free flaps are relatively complex, time consuming, and require microsurgical expertise [3,5].

The distally based peroneus brevis flap encounters the merits of expandable muscle with excellent reach, which was first described by Mathes and Nahai [5]. Moreover, this flap was further investigated and popularized by Eren et al., [7] and also by the follower Yang et al., [8]. Originally, the peroneus brevis was a type II muscle flap, but it was reclassified by Mathes and Nahai [6] as type IV with dominant pedicles originating from the peroneal artery proximally, entering the deep surface of the muscle, and distal minor pedicles from the peroneal or anterior tibial vessels. When the flap is based distally, it is recommended that three fingerbreadths be left intact from the distal tip of the lateral malleolus [7].

This flap is successfully used for tissue for defect coverage of small and moderate defects, with merits of constant vascular pattern, and straight forward and rapid elevation, with insignificant donor-site morbidity [9]. The authors tried to show their experience with 10 patients with soft tissue defects over the tendo-achilis, that were reconstructed successfully with no major complications, using the distally based peroneus brevis muscle flap.

\section{PATIENTS AND METHODS}

All cases were done in Ain shams University Hospitals, from May 2016 to September 2018. Ten cases with soft tissue defects over the tendo-achilis, were reconstructed using distally based peroneus brevis muscle. Seven males and three females shared in this study, with average age 24-56 years. The patients were followed-up to 5 months postoperatively. These defects were due to the trauma itself (6 cases) or following extensive dissection of the adherent skin over the tendo-achilis with resultant jeopardize of skin vascularity (3 cases). The surface area of the defects started from 10.56 and ranges up to $21.84 \mathrm{~cm}^{2}$.

Operation began with the debridement of the necrotic edges or tendons (Fig. 1), followed by reassessment of the dimensions of the defects. Application of tendon grafts in case of tendoachilis defects (2 cases). Doppler ultrasound was used before skin incision to detect reliable distant perforator for the flap and marked. Dissection of the flap was done under tourniquet. Skin incision was made $1 \mathrm{~cm}$ dorsal to a line drawn from the head to the tip of the fibula from the midleg, where 
the peroneus brevis muscle originates, to a point $3 \mathrm{~cm}$ above the tip of the fibula. After identification of the tendons of the peroneus longus and brevis muscles and isolation of the superficial peroneal nerve, dissection of the peroneus brevis muscle ensued separating it from the lateral surface of the fibula.

Around the distal third of fibula, approximately last $5 \mathrm{cms}$ to the lateral malleolus, the main vascular pedicle from the peroneal artery enters the muscle usually, which was dissected and carefully preserved. After complete dissection of the muscle from the fibula, the muscle flap is turned over defects of the tendo-achilis with opening of any skin bridges. Fixation with interrupted inverted absorpable stitches over the exposed tendo-achilis was done Fig. (2), the muscle flap was further covered using split-thickness skin grafts one week later (Fig. 3).

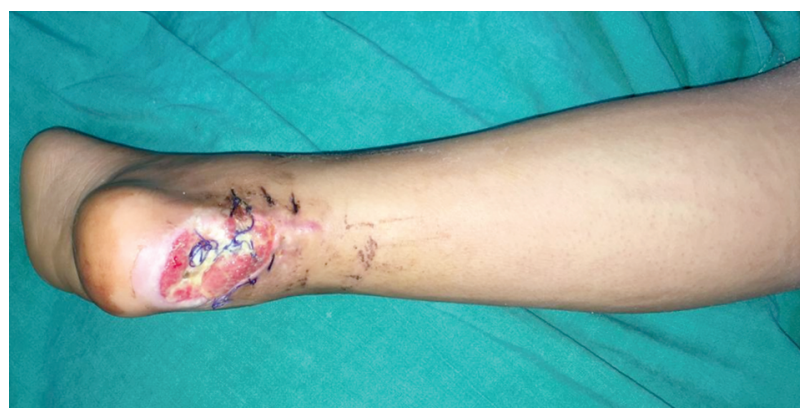

Fig. (1): Exposed repaired tendo-achilis.
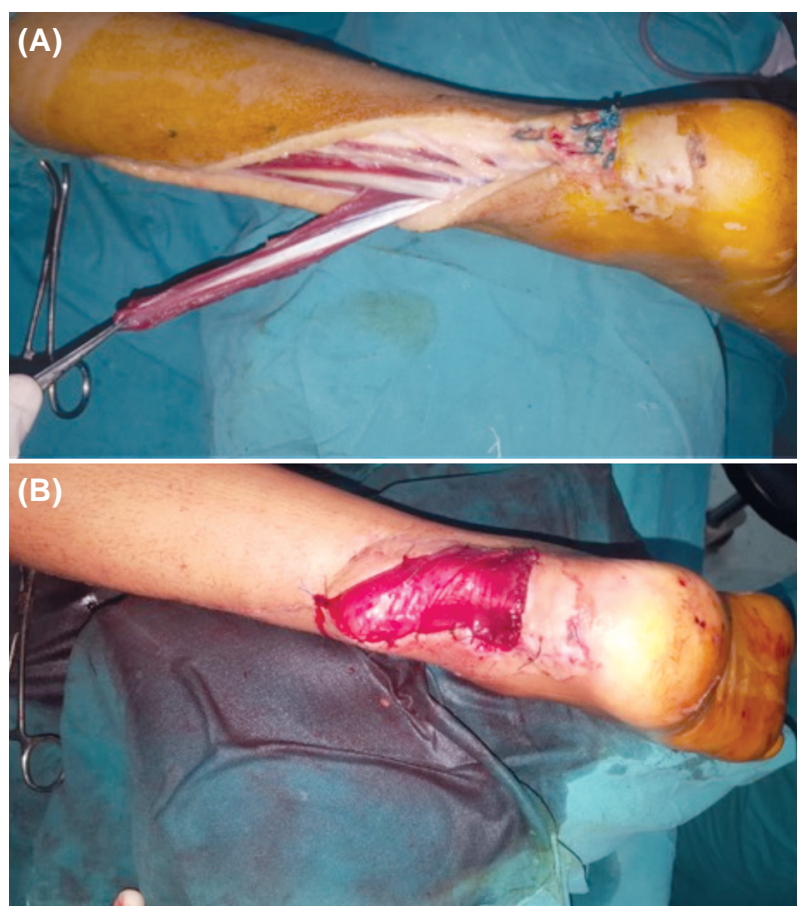

Fig. (2): (A) The upper shows the harvesting of the flap, (B) The lower shows inset of the flap.

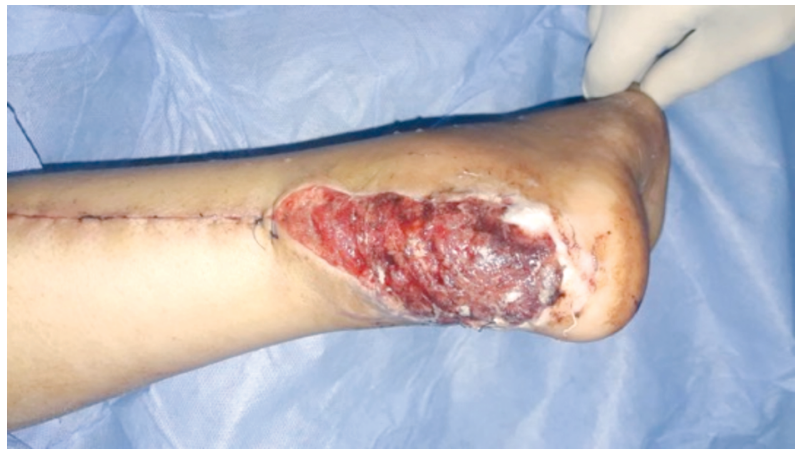

Fig. (3): The flap one week post-operative prior to skin grafting.

\section{RESULTS}

All defects were reconstructed by distally based peroneus brevis muscle flap then skin grafting one week later. Nine flaps survived completely, one flap only suffered from congestion and distal one $\mathrm{cm}$ loss, that was later advanced needing further reoperation. In two patient, hematoma occurred within the donor site, followed fortunately by early evacuation with no wound disruption or infection.

\section{DISCUSSION}

The intricate skin around the ankle and lower third of the leg imposes a challenge in case of soft tissue reconstruction, as this usually require flap coverage. There are options for reconstruction of soft tissue defects as fasciocutaneous, fascial, muscle. Though these flaps are numerable, their pedicles may be served in the zone of injury around the skin defect.

Muscle flaps remain often the first choice, when dealing with osteomyelitis, soft tissue infections, or large hollows [10]. Large skin defects are amenable to free flap coverage at the first place [11]. Yet, there are still disadvantages with free flaps; donor site morbidity, longer operation time, sacrifice of a major vessel of the leg and microsurgical skills [12]. Another option is the distally based peroneus brevis flap. The flap was formerly described by Mathes and Nahai [6]. Successively, this flap was then popularized by Eren et al., [7] and Yang et al., [8]. It has many values in comparison to other options as the flap elevation is fast and safe surgery, reliable coverage, without any sacrifice of major arteries of the leg. Moreover, donor-site morbidity is insignificant because the preserved peroneus longus muscle that maintains foot eversion [9].

Eren et al., [7] emphasized that the distal segmental branches of the peroneal provides a reliable 
blood supply to the whole muscle flap, which are located within three fingerbreadths proximal to the lateral malleolus. In our cases we found the main distal vascular pedicle that was mapped by Doppler ultrasound approximately within $4-5 \mathrm{~cm}$ proximal of the lateral malleolus. Yang et al., [8] indorsed preservation of the fibular attachment to the muscle in the distal $6 \mathrm{~cm}$ of the to assure the blood supply and to increase flap reliability.

In conclusion, the distally based peroneal muscle flap provides adequate coverage of the tendoachilis even in patients with vascular injury. Therefore, this flap offers a substantial alternative for covering defects in the region of tendo-achilis and is often preferable to the use of free flaps especially when dealing with small or moderate tissue defects over the tendo-achilis.

\section{REFERENCES}

1- Arnold P.G., Yugueros P. and Hanssen A.D.: Muscle flaps in osteomyelitis of the lower extremity: A 20-year account. Plast. Reconstr. Surg., 104: 107-10, 1999.

2- Kneser U., Bach A.D., Polykandriotis E., et al.: Delayed reverse sural flap for staged reconstruction of the foot and lower leg. Plast. Reconstr. Surg., 116: 1910-7, 2005.

3- Magdy Ahmed Abd Al-Moktader: Open-book Splitting of a Distally Based Peroneus Brevis Muscle Flap to Cover Large Leg and Ankle Defects. (Plast. Reconstr. Surg. Glob. Open December, 3: e572), 2015.
4- Gonzalez M.H., Tarandy D.I., Troy D., et al.: Free tissue coverage of chronic traumatic wounds of the lower leg. Plast. Reconstr. Surg., 109: 592-600, 2002.

5- Kuokkanen H.O., Tukiainen E.J. and Asko-Seljavaara S.: Radical excision and reconstruction of chronic tibial osteomyelitis with microvascular muscle flaps. Orthopedics, 25: 137-40, 2002.

6- Mathes S.J. and Nahai F.: Reconstructive Surgery: Principles, Anatomy and Technique. New York: ChurchillLivingstone, 1997.

7- Eren S., Ghofrani A. and Reifenrath M.: The distally pedicled peroneus brevis muscle flap: A new flap for the lower leg. Plast. Reconstr. Surg., 107: 1443-8, 2001.

8- Yang Y.L., Lin T.M., Lee S.S., et al.: The distally pedicled peroneus brevis muscle flap anatomic studies and clinical applications. J. Foot Ankle Surg., 44: 259-64, 2005.

9- Koski E.A., Kuokkanen H.O. and Tukiainen E.J.: Distallybased peroneus brevis muscle flap: A successful way of reconstructing lateral soft tissue defects of the ankle. Scand J. Plast. Reconstr. Surg. Hand Surg., 39: 299-301, 2005.

10- Attinger C. and Cooper P.: Soft tissue reconstruction for calcaneal fractures or osteomyelitis. Orthop. Clin. North Am., 32: 135-70, 2001.

11- Kuokkanen H.O., Tukiainen E.J. and Asko-Seljavaara S.: Radical excision and reconstruction of chronic tibial osteomyelitis with microvascular muscle flaps. Orthopedics, 25: 137-40, 2002.

12- Gonzalez M.H., Tarandy D.I., Troy D., et al.: Free tissue coverage of chronic traumatic wounds of the lower leg. Plast. Reconstr. Surg., 109: 592-600, 2002. 